\title{
Schreien und tanzen
}

\section{Peter Marko}

Dr. med., Mitglied des freiwilligen Hospizdienstes St. Gallen

In mehrerer Hinsicht ist Sterben eine Grenzsituation. Es ist eine schöne, nicht selten schwierige Aufgabe, dazu beizutragen, dass der Mensch auf eine möglichst würdige Art diese Welt verlässt. Stimmt es, dass jeder auf die Weise stirbt, wie er gelebt hat?

Vor dem Einsatz in einem Heim wurde ich gewarnt, dass die bald neunzigjährige Patientin zwar immer schwächer werde, aber für Unruhe könne sie noch sorgen. Sie schreie schon mehrere Abende, bis sie um Mitternacht einschlafe. Als ich um 20.00 Uhr kam, hörte ich ihre Stimme schon auf dem Gang. Es schien, als ob sie meine Anwesenheit nicht mehr wahrnehmen würde. Ich versuchte, sie auf verschiedene Art und Weise zu beruhigen. Ich sprach zu ihr, fragte, was ihr fehle, ohne eine Antwort zu bekommen. Ich nahm ihre Hand und streichelte sie vorsichtig, sang sogar etwas. Die beschränkte Qualität meiner Aufführung störte sie nicht, aber auch die anderen Bemühungen fruchteten nicht. Nur wenn sie ermüdete, hörte sie für eine Weile auf zu wimmern und eintönig zu schreien. Ich hoffte bei jeder Pause vergebens, sie schlafe endlich ein. Wie verabredet um $24.00 \mathrm{Uhr}$ verliess ich die arme Frau mehr seelisch als körperlich ermüdet und emotionell aufgewühlt und hoffte, sie würde diese Nacht ihre Ruhe und bald für immer finden.

Mehrere Fragen beschäftigten mich. Warum schreit diese Frau? Von der Pflegefachfrau erfuhr ich, dass sie kaum körperliche Schmerzen hat. Warum lindert man ihre Unruhe nicht? Hat sie sich oder ihre Angehörigen dagegen entschieden? Wie lange muss sie noch leiden? So möchte ich nicht enden.

Die nicht einmal sechzigjährige Frau wurde wegen eines bösartigen Hirntumors operiert und bestrahlt. Sie war «nicht gut im Kopf», verwirrt und konnte das Gleichgewicht nicht halten, also auch nicht gehen. Man wollte sie nicht im Bett einsperren, das hätte sie nicht ertragen. Ich sollte jedoch aufpassen, dass sie nicht aufsteht. Sonst sorgte ihr Mann für sie, der sogar ein Spitalbett im Zimmer hatte. Am selben Tag musste er etwas erledigen und übernachtete zu Hause. Vor dem Bett lag eine Matte, die sollte melden, falls sie doch aufstehen würde, wenn niemand bei ihr weilte. Ich stellte mich vor. Sie wunderte sich, was ich bei ihr wolle, auch wenn ich nicht der erste vom Dienst bei ihr war. Sie brauche mich nicht, meinte sie, ich könne gehen. Ich erwiderte, es sei für mich eine Freude, die drei Stunden mit ihr zu verbringen. Ob sie etwas dagegen habe, was sie verneinte. Die Wände waren voll von Fotografien. Ein schönes, modernes Haus mit einer grossen Terrasse, wahrscheinlich mit wunderbarem Blick auf den Bodensee, ein grosser Hund, sie mit ihrem Mann in den Ferien irgendwo im Süden, lustig und ausgelassen. Ein einziges Kind war auf der Seitenwand - ich wusste, mit dieser Frau sollte ich lieber nicht über Kinder sprechen. Aber wir fanden genug Gesprächsstoff und bald kamen ihre verspielten, anmutigen Seiten zum Vorschein. Plötzlich bat sie mich, ihr ihr Handy zu reichen. Sie wählte mehrmals etwas unbeholfen irgendeine Nummer, aber die Verbindung klappte nicht. Sie war unzufrieden, leicht verzweifelt, als ob das Gespräch enorm wichtig wäre, und fragte mich, ob ich ihr helfen könne. Ich sagte, ich könne es versuchen, auch wenn ich wenig Erfahrung mit Smartphones habe. Es gelang mir wie durch ein Wunder. Es war ihr Mann. Sie fragte ihn, wann er komme, war unzufrieden mit seiner Antwort und machte ihm Vorwürfe. Es entbrannte ein kleiner Streit. Es schien mir, er betrachte nicht ihren Zustand und bleibe als erfolgreicher Geschäftsmann der Realität treu, «nahm sie ernst» und wich nicht aus. Verärgert beendete sie das Gespräch. Ich wusste nicht, soll ich sie auf das Gespräch und ihre seelische Lage ansprechen. Plötzlich bat sie mich, das Radio einzuschalten. Zum Glück kamen auf einem Kanal Schlager aus unserer Jugend. Sie hellte auf, begann mitzusingen, was ich nach ihrer Aufforderung mit meinem falschen Brummen begleitete. Plötzlich setzte sie sich auf den Bettrand, ohne zu versuchen aufzustehen. Sie blieb folgsam und liebenswürdig, wie es vermutlich ihrer Natur entsprach. Kurz darnach begann sie auf der ausgeschalteten Meldematte im Rhythmus mit den Beinen zu «tanzen». Wie selbstverständlich forderte sie mich auf, es ihr gleich zu tun, was ich meinen beschränkten Fähigkeiten entsprechend auch tat und ihr gegenüber sitzend möglichst im Rhythmus mit den Füssen auf die Matte schlug. Eine Krankenschwester (Pflegefachfrau) kam, und wunderte sich, was wir da treiben. Die Patientin sagte mit Selbstverständlichkeit: Wir tanzen. Offensichtlich gefiel es der Schwester. Die Patientin war gelöst. Das Gespräch mit ihrem Mann, ihre Krankheit und ihr Zustand waren weit weg. Die Musik leider bald auch. Die Krankenschwester kam wieder, um die Patientin für die Nacht vorzubereiten. Diese Nacht schlief ich ausgezeichnet. Hoffentlich auch die Patientin. 